\title{
Evidence-Based Ethics for Neurology and Psychiatry Research
}

\author{
Scott Y. H. Kim \\ Department of Psychiatry, Bioethics Program, and Program for Improving Health Care Decisions, University of Michigan \\ Medical School, Ann Arbor, Michigan 48109
}

\begin{abstract}
Summary: American bioethics, historically arising out of theology and philosophy, has been dominated by the method of normative analysis. Ethics as policy, however, requires in addition a solid evidence base. This paper discusses the background conditions that make neurotherapeutics research particularly challenging. Three key ethical issues are discussed within an evidence-based ethics framework: the ethical challenges arising from changes in the financial incentive structures for academic researchers and their institutions, the challenges
\end{abstract}

of risk-benefit analysis for neurotherapeutics protocols testing innovative interventions, and the evolving issues surrounding impaired decision-making capacity and surrogate consent for research. For each of these issues, selected empirical data are reviewed, areas for further inquiry are noted, and the need for development of novel methods for bioethics policy research is discussed. Key Words: Research ethics, conflicts of interest, informed consent, risk-benefit analysis, neurotherapeutics.

\section{NEUROTHERAPEUTICS RESEARCH RAISES IMPORTANT ETHICAL ISSUES}

Neuropsychiatric disorders are highly prevalent conditions with significant morbidity yet only modestly effective treatments. In the fight against Alzheimer's disease (AD), Parkinson's disease (PD), or schizophrenia, for example, the suffering and loss caused by these diseases call for the development of truly innovative interventions. Testing such innovative approaches can carry risks of significant harm ${ }^{1,2}$ even while raising hopes for future benefits. ${ }^{3}$ Furthermore, the very nature of many neuropsychiatric disorders creates ethical complexity because many persons with such disorders have impaired cognition. If a patient's impairment is severe enough, he or she will be incompetent to give informed consent for research. ${ }^{4,5}$ In our society, surrogate or proxy consentbased research remains an area of unsettled policy. ${ }^{6}$ Finally, at a more speculative level, interventions that alter behavior, or even knowledge that can predict or explain behaviors, can challenge traditional norms of social regulation and interaction. ${ }^{7}$ Knowledge that tends to, or at least is perceived to have the potential to disrupt accepted social categories and standards can raise unex-

Address correspondence and reprint requests to Dr. Kim, Bioethics Program, University of Michigan Medical School, 300 North Ingalls Street, Room 7D, Ann Arbor, MI 48109-0429. E-mail: scottkim@med.umich.edu. pected ethical challenges. Although this article will not discuss this last issue further, it represents a unique ethical complication of neuropsychiatric research.

Ethical concerns in neurotherapeutics research are amplified when seen in the context of a broader societal focus on research ethics. Our society now pays unprecedented attention to research ethics (and to academic medicine in general) and the current focus arguably surpasses the research ethics debates of the late 1970s and early $1980 \mathrm{~s}^{8}$ National and international media are exquisitely attuned to research ethics and have had plenty about which to report, including the tragic deaths of two young volunteers ${ }^{9,10}$ and the shutting down of research at some of the nation's most prominent institutions for lapses in research ethics practices. ${ }^{10,11}$ In 2000 , the National Institutes of Health (NIH) began requiring education in the protection of human research participants from all of its applicants for funding. ${ }^{12}$ Institutional Review Boards (IRBs) will now have prospective evaluation and accreditation. ${ }^{13}$ The debate on conflicts of interest in scientific research continues to evolve. ${ }^{14,15}$ High-profile lawsuits against investigators, IRBs, and their institutions are becoming more frequent. ${ }^{16,17}$

\section{WHAT IS EVIDENCE-BASED ETHICS?}

Because ethics deals with normative issues of "what ought to be," it may seem odd to talk about "evidencebased" ethics. Because of its origins as a philosophical 
and theological response to public crises, ${ }^{8}$ American bioethics discourse has been dominated by theory. However, once one frames ethics in the public policy context, the need for good data becomes obvious. There are at least three types of evidence needed for ethics policy. First, accurate and up-to-date scientific information is the cornerstone of any ethical analysis of research protocols. This is especially important in the risk-benefit assessment of proposed studies. In this regard, as discussed below, remediable threats to scientific objectivity and independence raise serious ethical concerns. Second, in a liberal democracy such as ours, the values and perspectives of key stakeholders surrounding a particularly controversial moral situation constitute important data. In many research ethics dilemmas, there may not be a priori, principled answers available and the "correct" solution may be the one that optimizes in some politically acceptable way the actual values of the relevant stakeholders.

Third, as with any type of policy development and implementation, data are needed to ensure that proposed solutions are practicable. Sometimes empirical ethics research is criticized on the basis that just because something is the case does not imply that it ought to be the case. A less often taught principle is that "ought implies can", i.e., if something is not implementable, then there can be no obligation to implement it. What sounds good in theory can in fact produce counterproductive results if not implemented with a thorough understanding of the facts. Facts matter in ethics.

Ethical issues in clinical research generally fall under seven categories, as recently summarized by Emanuel et al. ${ }^{18}$ The research must 1 ) be socially or scientifically valuable, 2) have scientific validity, 3) have fair subject selection, 4) have favorable risk-benefit ratio, 5) undergo independent review, 6) obtain informed consent, 7) show respect for potential and enrolled subjects. Although all seven are important, three of the above requirements-scientific validity, favorable risk-benefit ratio, and informed consent-are of special interest for ethical evaluation of neurotherapeutics research, and are discussed in detail below. In the discussion of each domain, I illustrate what role evidence can play in the ethical analysis, either by applying existing evidence or by proposing areas of research. I highlight novel methods and areas of research when appropriate and emphasize the first two issues (scientific validity and risk-benefit analysis), whereas only briefly touching on the welltraversed terrain of informed consent.

\section{ETHICAL BASIS OF SCIENTIFIC ACTIVITY}

The requirement of scientific validity is an important reminder that science is an endeavor with inherent ethical obligations. The duties of objectivity, independence, and rigorous evaluation of data should be familiar to all who are concerned with the integrity of the scientific enterprise in any domain. Science is not a mere technical activity; it has ethical rules without which the activity would not qualify as science.

In this context, a source of ethical concern is the hotly debated issue of the influence of financial interests in biomedical research in domains that, until a couple of decades ago, operated relatively free from such incentives. In both basic and clinical research, the very structure of incentives for academic researchers (and their institutions) have undergone politically sanctioned changes. ${ }^{19-21}$ The trend is likely to continue and the conflicts will increase. The hope of this large-scale social experiment is that academia-industry synergy will produce benefits that outweigh the potential pitfalls. The primary potential pitfall is the loss of a socially sanctioned role, viz. the academic scientist (and institution) who is, and is perceived to be, an objective, independent arbiter of scientific claims. ${ }^{22}$ This role is part of the very idea of a "liberal" (i.e. , free and unfettered) university.

Why might neurotherapeutics research be especially prone to influence of financial incentives? First, neuropsychiatric disorders combine very high prevalence (because of both high incidence and chronicity, often occurring in the young) and morbidity. From an economic point of view, such disorders create an immense market for therapeutics, and even very small incremental (or even a perception of it) benefits can mean a significant marketing advantage. There is a lot of money at stake in neurotherapeutics research. Second, there is often room for interpretation-and controversy-over matters of diagnosis, symptom and functional measurement, standards for measuring the efficacy of interventions, and characterization of adverse effects of interventions. Some of the most prevalent neuropsychiatric disorders tend to be clinically defined syndromes rather than welldefined diseases. Even when the illness is well-defined biologically, clinical research involves considerable interpretation, as evidenced by the evolution of outcome measures for $\mathrm{AD}$ trials. ${ }^{23}$ The intrinsically gray areas of scientific opinion in a domain with enormous economic consequences create significant moral hazards.

What kind of ethics policy research is necessary in this regard? There is already a substantial body of literature on the effects of financial conflicts of interest on biomedical research. ${ }^{24}$ They range from detailed case studies, ${ }^{25-27}$ studies indicating influence of financial ties on scientific opinion ${ }^{28-30}$ and on delays in publishing, ${ }^{31}$ and reviews of how sponsorship can distort science. ${ }^{32,33}$

It may be that the biomedical research enterprise, as it moves closer to a business model, will engender its own domain of business ethics research, much in the way that psychologists and other social scientists in business schools conduct research on, for instance, the ethics of 
accounting. ${ }^{34-36}$ A great deal of recent focus has been on the psychology of moral decision-making and we can expect to see application of decision psychology and behavioral economics to conflict of interest policy research in biomedicine. ${ }^{37}$

On the other hand, it is also possible that such research may not flourish at all, given that there are important issues of institutional conflicts of interest, in which both academic institutions and professional societies have little financial incentive to promote such research. From an ethical point of view, the changing nature of the academic institutions needs to be accompanied by appropriate self-critical research endeavors. But the very nature of institutional conflicts of interest could potentially play a role in whether such endeavors are encouraged within the same institutions.

\section{FAVORABLE RISK-BENEFIT RATIO}

The ethical requirement of favorable risk-benefit ratio involves minimizing risks, enhancing potential benefits, and ensuring that the risks to the subjects are justified by the potential benefits to the subjects and/or society. ${ }^{18}$ Compared to the vast literature on informed consent, the scholarship on risk-benefit analysis in research ethics is comparatively thin. ${ }^{38,39}$ IRBs, however, tend to see a review of the risk-benefit ratio as one of the most important things they do. ${ }^{40,41}$

A persistent controversy exists in interpreting the federal requirement that the risks must be reasonable in relation to anticipated benefits, either to the subject directly or to society in the form of increased knowledge (45CFR46.111a). There are at least three relevant issues for neurotherapeutics research in this regard. First, when the research subjects lack decision-making capacity, it is not clear whether and how such risks can be balanced against the gain in scientific knowledge and benefit to future patients, i.e., when the protocol has no potential for direct benefit to the subjects or when the protocol is the very first human experiment whose main aim is to test the safety of the new intervention. ${ }^{2,42}$ Such persons need third party ("legally authorized representative") permission for participation in research and usually it is not known what the subject would have wanted. Third party consent in the medical treatment context is routine because there is a long-standing tradition of accepting such permission given that the decisions will be made in the best interests of the patients (if the principal's wishes are not known). In a research protocol with no potential for direct benefit to the subjects, however, the issue is how much risk and burden to the incapable subjects can be reasonably justified by the potential increase in knowledge (that will presumably benefit other patients). In research with children, the federal regulations impose the restriction that children may not be exposed to more than minor increase over minimal risk, when the research involves an intervention or procedure "that does not hold out the prospect of direct benefit" to the subjects (45CFR46.406). No analogous policy exists for research with incapacitated adults. ${ }^{43}$

Second, even for situations in which the subjects in neurotherapeutics research do have decision-making capacity, there have been prominent debates regarding whether certain types of research should be conducted at all. ${ }^{4-46}$ In randomized neurosurgical trials of tissue transplants for Parkinson's disease, the sham control subjects were exposed to procedures that carry risk but without potential for direct benefit. Such a control condition, however, may be invaluable in controlling for the placebo effect and the natural fluctuations in PD symptoms. ${ }^{46}$ Because a false positive result from a clinical trial can lead to a large number of unnecessary and even harmful surgeries, the gain in scientific knowledge (assuming that the sham control condition has such incremental knowledge advantage over open controls) could be substantial and not merely academic. Does this gain justify exposing such subjects to nonbeneficial procedures that carry risks?

Even if we accept the current practice of sham controls for PD research, there are future possibilities that raise thornier questions. For example, if a randomized controlled trial of gene transfer therapy for PD is proposed, what is the appropriate control condition? The range of possibilities include drilling of burr holes without interrupting the dura, adding probe manipulation into the striatum (or whichever structure is targeted for gene transfer), adding injection of the same vector medium without the vector, injecting an "empty" vector, and so on, even to the addition of a "placebo" gene that will insert into the genome but, presumably, will not produce the gene product in question.

Third, what is the best way of balancing risks and benefits when thinking about early phase research? Is it appropriate to conduct human studies based only on rodent data? ${ }^{47}$ Most phase I studies are conducted in healthy volunteers. The most well established paradigm for phase I studies involving patients (rather than healthy volunteers) is in cancer dose-escalation protocols. ${ }^{48}$ That paradigm does allow a relatively separate evaluation of safety and efficacy. It does not however capture well the riskbenefit evaluation of interventions such as gene transfer or tissue transplants. For instance, if in a phase I trial of gene transfer protocol there were absolutely no suggestion of benefit from the intervention, is it the same situation as finding no suggestion of efficacy in a cancer phase I trial?

Finally, once an effective treatment is found, the testing of newer and, hopefully, better interventions can become ethically problematic, if the scientifically optimal design is a placebo control (for example, if the outcome variable is known to be susceptible to the placebo effect and tends to have wide natural fluctuations). 
Withholding of effective treatments for research purposes can become an issue in another mode, because the notion of neuroprotection is particularly relevant to neurodegenerative disorders and the testing of an effective agent for its putative neuroprotective effects will involve withholding of such a drug.

What kind of evidence is needed to aid policy in this area? It is worth reiterating that the most ethically relevant evidence is accurate, current scientific data. However, ultimately, what constitutes an acceptable risk-benefit tradeoff is a matter of social policy, not just of scientific expertise. Ideally, such policy should be informed by the views of the stakeholders. The most established method for eliciting such views is the survey. Surveys of potential research participants can give useful data that is distinct from any conclusions that can be drawn from the fact that patients do in fact enroll in research studies. ${ }^{49}$ Surveys of IRB members or scientists and scientific administrators regarding how they apply the risk-benefit analysis regulations can also illuminate how policies may in fact get applied. ${ }^{50}$ Surveys of the general public on the appropriateness of certain implied tradeoffs in research protocols can also inform the debate.

In general, however, the methodology for eliciting public opinion on complex policy questions is not well developed in bioethics research. Although surveys are useful, they provide a rather thin description. Many bioethics policy issues are not everyday issues for which we would expect informed or even formed opinions in lay persons. In this regard, bioethics needs to borrow methods from other social science disciplines that aim to elicit views that are richer than surveys and yet more generalizable than focus groups. Some social scientists now aim to elicit "constructed preferences" using methods that do not assume preformed ethical opinions. ${ }^{51,52}$ Political scientists have long discussed the notion of deliberative democracy ${ }^{53,54}$ in which policies are developed or informed by citizens deliberating together guided by certain normative principles of deliberation. ${ }^{54}$ This tradition has developed a well-articulated theory about how to address ethical controversies in a liberal democracy. ${ }^{55}$ Empirical research methods using the deliberative democracy framework are now beginning to be used in health care policy. ${ }^{53}$ The basic idea is that a group of representative citizens (or from the ethically relevant stakeholder groups) are brought together to engage in in-depth education, discussion, and argumentation (in the sense of giving and receiving varying viewpoints and reasons for and against various policies). Not only individual but group level outcomes can be measured.

\section{INFORMED CONSENT}

Informed consent requires three elements. The subjects must be "accurately informed of the purpose, meth- ods, risks, benefits, and alternatives to research," have intact decision-making capacity, and make a voluntary choice. ${ }^{18}$ There is nothing unique about information disclosure requirements for neurotherapeutics research; the federal guidelines are explicit about the content (45CFR46.116). Voluntariness is a rather difficult concept to operationalize, and is the least developed conceptually. ${ }^{56,57}$ The federal regulations mention its conceptual cousin-viz., vulnerability to coercion and undue influence in subjects who are "mentally disabled" and require "additional safeguards" (45CFR46.111b) — but it is not clear what these safeguards might be. Some argue that the serious, incurable nature of many neuropsychiatric disorders place patients in particularly vulnerable positions for exploitation. ${ }^{44}$ Assuming that the notion of vulnerability can be reasonably operationalized, this claim should be open to future study.

The aspect of informed consent receiving growing attention in recent years is decision-making capacity. There is an emerging literature of empirical studies on decision-making capacity, although quite varied in quality, conceptual frameworks, and methodology; these studies have been reviewed elsewhere. ${ }^{58}$ Here I briefly summarize the key findings to date and point out questions that need further research.

The two medical conditions that have received the most attention by researchers is schizophrenia and Alzheimer's disease, although sporadic studies have been done on the influence of other conditions on decisional capacity (such as depression ${ }^{59}$ and Parkinson's disease $\left.{ }^{60}\right)$. In schizophrenia, the three emerging findings have been that, first, although persons with schizophrenia, as a group, perform more poorly on tests of decisional abilities than comparable normal controls, many retain their abilities to give informed consent fairly well. ${ }^{5,61}$ Second, most persons with schizophrenia seem to respond well to education aimed at improving performance, at least in terms of increasing their factual understanding of disclosed information., ${ }^{5,61-63}$ Third, by and large, decisional impairment tends to be best predicted by cognitive impairment rather than by symptoms of psychosis. 5

In Alzheimer's disease, the decisional impairment is more severe. Even in fairly early stages of the disease, a significant portion has difficulty understanding, appreciating, and reasoning about informed consent to research. ${ }^{4,64}$ In $\mathrm{AD}$, because loss of cognition tracks loss of decisional abilities fairly well, it may be possible to develop efficient, targeted screening strategies, although more research needs to confirm this possibility. ${ }^{65}$ There is a paucity of data on whether persons in early stages of $\mathrm{AD}$ would benefit from remedial education to enhance decision-making abilities. ${ }^{58}$

A consistent finding in capacity research is an empirical confirmation of the normative principle that a clin- 
ical diagnosis does not imply decisional incapacity; the latter must be assessed on its own terms. This finding confirms the complex nature of evaluating someone's decision-making capacity status. There is a continuing need for research that targets specific decision points that arise in the course of conducting research with decisionally impaired persons. Some examples are, as follows:

- How should impairment be translated into incapacity $?^{58}$ Decisional impairment is a dimensional concept but persons are either allowed or not allowed to give informed consent. Only preliminary data exist to guide this translation of dimensional data on impairment into a categorical decision about a person's decision-making authority.

- How should the intensity of capacity evaluation process be adjusted according to the risk-benefit ratio of the proposed protocol?

- How can screening for incapacity be conducted so that it is both ethically valid and procedurally efficient?

- What is the relationship between the capacity to give informed consent and the capacity to appoint a proxy agent who makes a decision for the subject? For instance, if the standard for appointing a proxy is more easily met than the standard for giving one's own consent, as theory would suggest, ${ }^{66}$ then a better understanding of proxy appointing capacity may allow more finegrained protection for the impaired person while at the same time allowing ethical enrollment of impaired persons in research.

\section{SUMMARY AND CONCLUSION}

Our society urgently needs innovative neurotherapeutics research but such research involves significant ethical challenges. The starting point for meeting these challenges is the preservation of objective and independent scientific activity and opinion. The changing financial incentive structures in the academia have launched a de facto social experiment. One key area for ethics scholarship is to gather evidence that will allow our society to gauge the outcome of this experiment. The solutions to the other ethical challenges, such as the challenges of risk-benefit analysis and issues surrounding decisionmaking capacity and surrogate consent for research, in no small way depend on how credible academic researchers and their institutions remain in the eyes of society.

Acknowledgments: This work was supported in part by Grants MH64172 and NS45309 from the National Institutes of Health.

\section{REFERENCES}

1. Orgogozo JM, Gilman S, Dartigues JF, Laurent B, Puel M, Kirby LC et al. Subacute meningoencephalitis in a subset of patients with AD after A $\beta 42$ immunization. Neurology 61:46-54, 2003.
2. Silverberg GD, Levinthal E, Sullivan EV, Bloch DA, Chang SD, Leverenz $\mathbf{J}$ et al. Assessment of low-flow CSF drainage as a treatment for AD: results of a randomized pilot study. Neurology 59:1139-1145, 2002.

3. Hock C, Konietzko U, Streffer J, Tracy J, Signorell A, MullerTillmanns B et al. Antibodies against $\beta$-amyloid slow cognitive decline in Alzheimer's disease. Neuron 38:547-554, 2003.

4. Kim SYH, Caine ED, Currier GW, Leibovici A, Ryan JM. Assessing the competence of persons with Alzheimer's disease in providing informed consent for participation in research. $\mathrm{Am} \mathrm{J}$ Psychiatry 158:712-717, 2001.

5. Carpenter WT Jr, Gold J, Lahti A, Queern C, Conley R, Bartko J et al. Decisional capacity for informed consent in schizophrenia research. Arch Gen Psychiatry 57:533-538, 2000.

6. National Bioethics Advisory Commission. Research involving persons with mental disorders that may affect decision making capacity, Vol 1, report and recommendations of the National Bioethics Advisory Commission. Rockville, MD: NBAC, 1998.

7. Neuroethics: mapping the field: conference proceedings, May 1314, 2002, San Franciso, California (Marcus S, ed). New York: The Dana Press, 2002.

8. Jonsen AR. The birth of bioethics. New York: Oxford University Press, 1998.

9. Stolberg SG. The biotech death of Jesse Gelsinger. $N$ Y Times Mag Nov 28:136-140, 149-150, 1999.

10. Kolata G. Johns Hopkins Death Brings Halt to U.S.-financed human studies. N Y Times Mag Jul 20:A1, A18, 2001.

11. Marshall E. Shutdown of research at Duke sends a message. Science 284:1999.

12. National Institutes of Health. Required education in the protection of human research participants. NOTICE: OD-00-039, June 5, 2000 .

13. Association for the Accreditation of Human Research Protection Programs, Inc. AAHRPP website, 2002.

14. Task Force on Financial Conflicts of Interest in Clinical Research. Protecting subjects, preserving trust, promoting progress-policy and guidelines for the oversight of individual financial interest in human subjects research. Association of American Medical Colleges, 2001.

15. Task Force on Research Accountability. Report on individual and institutional financial conflict of interest. Association of American Universities, 2001.

16. Wilson D, Heath D. Class-action suit filed against 'The Hutch'. Seattle Times Mar 27, 2001.

17. Mello MM, Studdert D, Brennan TA. The rise of litigation in human subjects research. Ann Intern Med 139:40-45, 2003.

18. Emanuel EJ, Wendler D, Grady C. What makes clinical research ethical? JAMA 283:2701-2711, 2000 .

19. Blumenthal D. Ethics issues in academic-industry relationships in the life sciences: the continuing debate. Acad Med 71:1291-1296, 1996.

20. Emanuel EJ, Steiner D. Institutional conflict of interest. $N$ Engl J Med 332:262-267, 1995.

21. Frankel MS. Perception, reality, and the political context of conflict of interest in university-industry relationships. Acad Med 71: 1297-1304, 1996.

22. Munro N. Doctor Who? Washington Monthly Nov 2002.

23. Karlawish J. The search for a coherent language: the science and politics of drug testing and approval. In: Ethics, law, and aging review, Vol 8, Issues in conducting research with and about older persons (Kapp MB, ed), pp 39-56. New York: Springer, 2002.

24. Bekelman JE, Li Y, Gross CP. Scope and impact of financial conflicts of interest in biomedical research: a systematic review. JAMA 289:454, 2003.

25. Nathan DG, Weatherall DJ. Academic freedom in clinical research. N Engl J Med 347:1368-1371, 2002.

26. Shuchman M. Legal issues surrounding privately funded research cause furore in Toronto. CMAJ 159:983-986, 1998.

27. Rennie D. Thyroid storm. JAMA 277:1238-1243, 1997.

28. Stelfox H, Chua G, O'Rourke K, Detsky A. Conflict of interest in the debate over calcium-channel antagonists. N Engl J Med 338: 101-106, 1998. 
29. Levine J, Gussow JD, Hastings D, Eccher A. Authors' financial relationships with the food and beverage industry and their published positions on the fat substitute olestra. Am J Public Health 93:664, 2003

30. Pieters T. Marketing medicines through randomised controlled trials: the case of interferon. Br Med J 317:1231-1233, 1998.

31. Blumenthal D. Academic-industry relationships in the life sciences. Extent, consequences, and management. JAMA 268:33443349, 1992

32. Safer DJ. Design and reporting modifications in industry-sponsored comparative psychopharmacology trials. J Nerv Ment Dis 190:583-592, 2002.

33. Baker CB, Johnsrud MT, Crismon ML, Rosenheck RA, Woods SW. Quantitative analysis of sponsorship bias in economic studies of antidepressants. Br J Psychiatry 183:498-506, 2003.

34. Libby R, Bloomfield R, Nelson M. Experimental research in financial accounting. Accounting, Organizations and Society 27: 775-810, 2002.

35. Bazerman M, Loewenstein G, Moore D. Why good accountants do bad audits. Harv Bus Rev 80:96-102, 134, 2002.

36. Messick DM, Bazerman MH. Ethical leadership and the psychology of decision making. Sloan Manage Rev 37:9-22, 1996.

37. Dana J, Loewenstein G. A social science perspective on gifts to physicians from industry. JAMA 290:252, 2003.

38. Sugarman J, Faden R, Weinstein J. A decade of empirical research in medical ethics. In: Methods in medical ethics (Sugarman J, Sulmasy DP, eds), pp 19-28. Washington, DC: Georgetown University Press, 2001

39. Weijer $\mathrm{C}$. Thinking clearly about research risk: implications of the work of Benjamin Freedman. IRB 21:1-5, 1999.

40. Keyserlingk EW. Proposed guidelines for the participation of persons with dementia as research subjects. Perspect Biol Med 38: 319-362, 1995.

41. Meslin E, Lavery J, Sutherland H, Till J. Judging the ethical merit of clinical trials: what criteria do research ethics board members use? IRB 16:6-10, 1994

42. Sunderland T, Linker G, Mirza N, Putnam KT, Friedman DL, Kimmel LH et al. Decreased $\beta$-amyloid1-42 and increased tau levels in cerebrospinal fluid of patients with Alzheimer disease. JAMA 289:2094-2103, 2003.

43. Kim SYH, Appelbaum PS, Jeste DV, Olin J. Proxy and surrogate consent in geriatric neuropsychiatric research: update and recommendations. Am J Psychiatry 161:797-806, 2004.

44. Macklin R. The ethical problems with sham surgery in clinical research. N Engl J Med 341:992-996, 1999.

45. Weijer C. I need a placebo like I need a hole in the head. $J$ Law Med Ethics 30:69-72, 2002.

46. Albin RL. Sham surgery controls: intracerebral grafting of fetal tissue for Parkinson's disease and proposed criteria for use of sham surgery controls. J Med Ethics 28:322-325, 2002.

47. Grady D, Kolata G. Gene therapy used to treat patients with Parkinson's. N Y Times Mag Aug 19, 2003.

48. Miller M. Phase I oncology trials. In: Institutional review board: management and function (Amdur R, Bankert E, eds), pp 465-475. Sudbury, Massachusetts: Jones and Bartlett, 2002.
49. Wendler D, Martinez RA, Fairclough D, Sunderland T, Emanuel E. Views of potential subjects toward proposed regulations for clinical research with adults unable to consent. Am J Psychiatry 159:585-591, 2002.

50. Janofsky J, Starfield B. Assessment of risk in research on children. J Pediatr 98:842-846, 1981.

51. Payne J, Bettman J, Schkade D. Measuring constructed preferences: toward a building code. J Risk Uncertain 19:243-270, 1999.

52. Fischhoff B. Cognitive processes in stated preference methods. In: Handbook of environmental economics (Mäler K-G, Vincent J, eds). North-Holland: Elsevier, 2002.

53. Abelson J, Forest PG, Eyles J, Smith P, Martin E, Gauvin FP. Deliberations about deliberative methods: issues in the design and evaluation of public participation processes. Soc Sci Med 57:239_ 251, 2003.

54. Gutmann A, Thompson D. Deliberating about bioethics. Hastings Cent Rep 27:38-41, 1997.

55. Gutmann A, Thompson D. Democracy and disagreement. Cambridge, MA: Harvard University Press, 1996.

56. Nelson RM. Voluntariness of consent for research: an empirical and conceptual review. Med Care 40[Suppl 9]:V69-V80, 2002.

57. Roberts LW. Informed consent and the capacity for voluntarism. Am J Psychiatry 159:705-712, 2002.

58. Kim SYH, Karlawish JHT, Caine ED. Current state of research on decision-making competence of cognitively impaired elderly persons. Am J Geriatr Psychiatry 10:151-165, 2002.

59. Appelbaum PS, Grisso T, Frank E, O’Donnell S, Kupfer D. Competence of depressed patients for consent to research. Am J Psychiatry 156:1380-1384, 1999.

60. Dymek M, Atchison P, Harrell L, Marson DC. Competency to consent to medical treatment in cognitively impaired patients with Parkinson's disease. Neurology 56:17-24, 2001.

61. Moser DJ, Schultz SK, Arndt S, Benjamin ML, Fleming FW, Brems CS et al. Capacity to provide informed consent for participation in schizophrenia and HIV research. Am J Psychiatry 159: 1201-1207, 2002.

62. Dunn LB, Lindamer LA, Palmer BW, Schneiderman LJ, Jeste DV Enhancing comprehension of consent for research in older patients with psychosis: a randomized study of a novel consent procedure. Am J Psychiatry 158:1911-1913, 2001.

63. Wirshing DA, Wirshing WC, Marder SR, Liberman RP, Mintz J. Informed consent: assessment of comprehension. Am J Psychiatry 155:1508-1511, 1998.

64. Marson DC, Ingram KK, Cody HA, Harrell LE. Assessing the competency of patients with Alzheimer's disease under different legal standards. A prototype instrument. Arch Neurol 52:949-954, 1995.

65. Kim S, Caine ED. Utility and limits of the mini mental state examination in evaluating consent capacity in Alzheimer's disease. Psychiatr Serv 53:1322-1324, 2002.

66. Mezey M, Teresi J, Ramsey G, Mitty E, Bobrowitz T. Decisionmaking capacity to execute a health care proxy: development and testing of guidelines. J Am Geriatr Soc 48:179-187, 2000. 